\title{
THE INFLUENCE OF VIBRATION-ROTATION INTERACTION ON BAND INTENSITY PARAMETERS FOR ZrO AND $\mathrm{CuH}^{*}$
}

\author{
J. A. C. Gallas, $\dagger$ R. E. Francke, H. P. Grieneisen, and B. P. Chakraborty \\ Instituto de Química and Instituto de Física, Universidade Federal do Rio Grande do Sul, Porto Alegre, Brazil \\ Received 1978 August 17; accepted 1978 October 5
}

\begin{abstract}
Effects of vibration-rotation interaction have been studied on the band intensity parameters of $\mathrm{ZrO}$ and $\mathrm{CuH}$ molecules. Band strengths have been calculated for the $\mathrm{ZrO} \alpha\left(C^{3} \Delta-X^{\prime}{ }^{3} \Delta\right)$ band system, and, in the absence of an electronic transition moment function, Franck-Condon factors and $\bar{r}$-centroids are reported for the $\mathrm{ZrO} \beta, \gamma, A$, and $B$ and the $\mathrm{CuH}\left(A^{1} \Sigma^{+}-X^{1} \Sigma^{+}\right)$band systems. RKR and Morse potentials are given for all the electronic states involved.
\end{abstract}

Subject headings: molecular processes - transition probabilities

\section{INTRODUCTION}

In this paper we report an investigation of the effect of vibration-rotation interaction upon the FranckCondon factors (FCF) and $\bar{r}$-centroids of $\mathrm{CuH}(A-X)$ and $\mathrm{ZrO}(\alpha, \beta, \gamma, A$, and $B)$ band systems, and upon the band strength of $\mathrm{ZrO}(\alpha)$ band. The $\mathrm{ZrO}$ molecule is known to be an important component of the late type stars, and its spectrum is of considerable importance in distinguishing $M$ and $S$ stars as shown by Keenan and Morgan (1951). The renewed interest in the study of electronic transitions of the $\mathrm{ZrO}$ band system has been justified by Schoonveld and Sundaram (1974). Hauge (1971) showed the existence of the 0-0 band of the $\mathrm{CuH}\left(A^{1} \Sigma^{+}-X^{1} \Sigma^{+}\right)$system in the sunspot spectrum. He also reported, with considerable uncertainty, the presence of the 1-1 band. Recently Wojslaw and Perry (1976) have identified the $0-0$ band together with the 1-0 and 1-1 bands of this system in the spectrum of 19 Piscium. They have also reported the peculiar $J$-variation of the observed intensities of the 0-0 band. In a recent review Nicholls (1977) stressed the importance of reliable FCFs and related quantities of astrophysically important molecules, including $\mathrm{CuH}$. Previous calculations of FCFs for $\mathrm{ZrO}$ (Singh and Pathak 1967a, $b$; Nicholls and Tyte 1967; Liszt and Smith 1971; Schoonveld and Sundaram 1974) did not include the effect of molecular rotation which is important in deriving excitation temperatures (Learner 1962) and isotopic abundances (Keenan and Morgan 1951). For $\mathrm{CuH}$, to our knowledge, there are no FCFs available in the literature. Therefore we undertake this study of the effect of molecular rotation on the band intensity parameters for both $\mathrm{ZrO}$ and $\mathrm{CuH}$ molecules. The rotational dependences have been studied for vibrational quantum numbers up to 10 and high $J$ (0-100 for $\mathrm{ZrO}$ and $0-60$ for $\mathrm{CuH}$, with an increment of 5).

* Work supported in part by CNPq and FINEP. Part of the paper was presented in the 30th Annual Conference of the Brazilian Society for the Progress of Science, São Paulo, 1978 July 9-15.

$\uparrow$ CNPq Predoctoral Fellow.

\section{THEORY}

The integrated intensity of a band of frequency $\nu^{v^{\prime} J^{\prime}}{ }_{v^{\prime \prime} J^{\prime \prime}} \mathrm{cm}^{-1}$ due to an electronic transition between upper level $v^{\prime} J^{\prime}$ and lower level $v^{\prime \prime} J^{\prime \prime}$, in emission, is given by

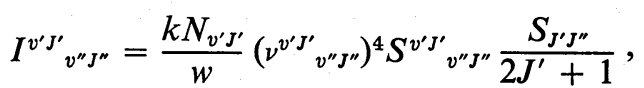

where $N_{v^{\prime} J}$ is the population of the upper state, $k$ is a constant, $w$ is the degeneracy of the upper state, and $S^{v^{\prime} J^{\prime}} v^{\prime \prime \prime} J^{\prime \prime}$ is the band strength, given by

$$
S^{v^{\prime} J^{\prime}{ }_{v^{\prime \prime} J^{\prime \prime}}}=\left|\int_{0}^{\infty} \Psi_{v^{\prime} J^{\prime}} R_{e}(r) \Psi_{v^{\prime \prime} J^{\prime \prime}} d r\right|^{2} .
$$

The factor $S_{J^{\prime} J^{\prime \prime}}$, called the Hönl-London factor, is well known for the most important electronic transitions and can be found, e.g., in a paper by Tatum (1967). The band strength $S^{v^{\prime} J^{\prime}}{ }_{v^{\prime \prime}} J^{\prime \prime}$ is an average with respect to upper and lower wave functions, $\Psi_{v^{\prime} j^{\prime}}$ and $\Psi_{v^{\prime \prime} j^{\prime \prime}}$, respectively, of the electronic transition moment $R_{e}(r)$, which is given by

$$
R_{e}(r)=\int \Psi_{U}^{*}(\Sigma-e r) \Psi_{L} d \tau_{e},
$$

and which is also an average of electronic dipole moment with respect to upper $\left(\Psi_{U}\right)$ and lower $\left(\Psi_{L}\right)$ electronic wave functions.

In cases where the electronic transition moment $R_{e}(r)$ is independent of $r$, or the dependence is unknown, equation (2) can be written as

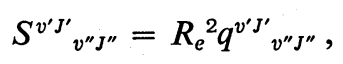

where $q^{v^{\prime} J^{\prime}}{ }_{v^{\prime \prime} J^{\prime \prime}}$ is known as the Franck-Condon factor (FCF) with the vibration-rotation interaction, and is given by

$$
q^{v^{\prime} J^{\prime \prime}{ }^{\prime \prime} J^{\prime \prime}}=\left|\int_{0}^{\infty} \Psi_{v^{\prime} J^{\prime}} \Psi_{v^{\prime \prime} J^{\prime \prime}} d r\right|^{2}
$$


TABLE 1

SPectroscopic Constants for ZrO and CuH Used in ThIS WorK*

\begin{tabular}{|c|c|c|c|c|c|}
\hline $\begin{array}{l}\text { Electronic } \\
\text { State }\end{array}$ & $\omega_{e}\left(\mathrm{~cm}^{-1}\right)$ & $\omega_{e} x_{e}\left(\mathrm{~cm}^{-1}\right)$ & $B_{e}\left(\mathrm{~cm}^{-1}\right)$ & $\alpha_{e}\left(\mathrm{~cm}^{-1}\right)$ & $r_{e}(\AA)$ \\
\hline \multicolumn{6}{|l|}{ ZrO: } \\
\hline$C^{3} \Delta \ldots \ldots$ & 819.83 & 3.150 & 0.39373 & 0.0021 & 1.775 \\
\hline$B^{3} \Pi \ldots .$. & 845.58 & 3.602 & 0.40395 & 0.0023 & 1.755 \\
\hline$A^{3} \Phi \ldots \ldots$ & 856.12 & 3.430 & 0.40459 & 0.0022 & 1.752 \\
\hline$X^{\prime}{ }^{3} \Delta \ldots \ldots$ & 937.36 & 3.487 & 0.41575 & 0.0021 & 1.728 \\
\hline$d^{1} \Delta \ldots \ldots$ & 839.2 & 2.56 & 0.399 & 0.0017 & 1.764 \\
\hline$c^{1} \Delta \ldots \ldots$ & 938.1 & 1.80 & 0.417 & 0.0012 & 1.725 \\
\hline$b^{1} \Sigma^{+} \ldots \ldots$ & 943.75 & 3.15 & 0.395 & 0.0020 & 1.772 \\
\hline$X^{1} \Sigma+\ldots \ldots$ & 976.51 & 3.462 & 0.423608 & 0.001954 & 1.712 \\
\hline \multicolumn{6}{|l|}{ CuH: } \\
\hline$X^{1} \Sigma^{2}+\ldots$ & $\begin{array}{l}1698.4 \\
1940.4\end{array}$ & $\begin{array}{l}44.0 \\
37.0\end{array}$ & $\begin{array}{l}6.875 \\
7.938\end{array}$ & $\begin{array}{l}0.263 \\
0.249\end{array}$ & $\begin{array}{l}1.5721 \\
1.4631\end{array}$ \\
\hline
\end{tabular}

In previous publications (Chang and Karplus 1970; Chakraborty, Pan, and Chang 1971; Gallas, Grieneisen, and Chakraborty 1978) analytical expressionsi.e., working equations to calculate FCFs, $\bar{r}$-centroids, and band strengths - have been reported in detail and are not reproduced here. For this purpose we particularly refer to the article of Gallas, Grieneisen, and Chakraborty (1978). ${ }^{1}$ The calculation of the FCFs is based on the assumption of a Morse-Pekeris molecular potential and in the use of asymptotic expansion techniques to evaluate expression (2). It is worthwhile to mention that expression (2) was used to calculate the band strength, without the usual $\bar{r}$ centroid approximation.

\section{DISCUSSION}

The molecular data needed to calculate the intensity parameters are given in Table 1; the electronic states

${ }^{1}$ Note in this reference that the expressions for $E_{0}$ and $E_{1}$ following equation (6) should read

$E_{0}=3 b_{4} / 4 b_{2}^{2}-15 b_{3}^{2} / 16 b_{2}^{3}$,

$E_{1}=-\left[a_{1}\left(3 b_{3} / 4 b_{2}+1 / 4 t_{\theta}\right)+a_{2}\left(3 b_{3} \rho_{0} / 2 b_{2}+\rho_{0} / 2 t_{0}+1 / 2 a^{\prime} t_{0}\right)\right]$

$\times\left[a^{\prime} t_{0} b_{2} R_{e}\left(\rho_{0}\right)\right]^{-1}$. involved in the $\alpha, \beta, \gamma, A$, and $B$ band systems of $\mathrm{ZrO}$ can be seen in Table 2. Spectroscopic constants for the ZrO triplet states $\left(C^{3} \Delta, B^{3} \pi, A^{3} \Phi, X^{\prime}{ }^{3} \Delta\right)$ are taken from the recent critical analysis of available experimental data made by Schoonveld and Sundaram (1974). For the $d ; c$, and $b$ singlet states we use the constants given by Nicholls and Tyte (1967). The $B_{e}$ values for these singlet states given in Table 1 were calculated through

$$
B_{e}=\left\{\mu\left(0.243559 r_{e}\right)^{2}\right\}^{-1},
$$

and the $\alpha_{\theta}$ were calculated using Pekeris's relation

$$
\alpha_{e} \equiv 6 B_{e}{ }^{2}\left\{\left(\omega_{e} x_{e} / B_{e}\right)^{1 / 2}-1\right\} / \omega_{e}
$$

Previously the lower electronic state of the $\mathrm{ZrO} A$ band system was designated by Uhler and Åkerlind (1956) as an $a\left({ }^{1} \Sigma\right.$ or $\left.{ }^{1} \Delta\right)$ state. This state has been recently studied by Balfour and Tatum (1973) in connection with a new ${ }^{1} \Pi-{ }^{1} \Sigma$ transition, and by Phillips and Davis (1976a) in connection to another new ${ }^{1} \Sigma-1 \Sigma$ transition. This state, now called $X^{1} \Sigma^{+}$, is presently thought to be the $\mathrm{ZrO}$ ground state (Veits et al. 1974). Therefore, in calculating the intensity parameters for the $A$ band system of $\mathrm{ZrO}$ we used the

TABLE 2

\begin{tabular}{|c|c|c|c|c|c|c|c|c|c|}
\hline Band System & $\boldsymbol{J}$ & $0-0$ & $0-1$ & $1-0$ & $1-1$ & $2-3$ & $3-5$ & $4-5$ & $6-6$ \\
\hline \multirow[t]{2}{*}{$\alpha, C^{3} \Delta-X^{\prime}{ }^{3} \Delta}$, & $\begin{array}{r}0 \\
50\end{array}$ & $\begin{array}{l}0.6753 \\
0.6689\end{array}$ & $\begin{array}{l}0.2674 \\
0.2715\end{array}$ & $\begin{array}{l}0.2618 \\
0.2654\end{array}$ & $\begin{array}{l}0.2473 \\
0.2373\end{array}$ & $\begin{array}{l}0.3282 \\
0.3252\end{array}$ & $\begin{array}{l}0.2281 \\
0.2317\end{array}$ & $\begin{array}{l}0.1737 \\
0.1653\end{array}$ & $\begin{array}{l}0.1067 \\
0.1126\end{array}$ \\
\hline & 100 & 0.6497 & 0.2834 & 0.2757 & 0.2086 & 0.3147 & 0.2417 & 0.1402 & $\begin{array}{l}0.1126 \\
0.1285\end{array}$ \\
\hline \multirow[t]{3}{*}{$\beta, B^{3} \Pi-X^{\prime 3} \Delta \ldots$} & 0 & 0.8742 & 0.1166 & 0.1179 & 0.6497 & 0.2691 & 0.0733 & 0.3264 & 0.0474 \\
\hline & $\begin{array}{r}50 \\
100\end{array}$ & 0.8697 & 0.1206 & 0.1218 & 0.6383 & 0.2750 & 0.0771 & 0.3286 & 0.0386 \\
\hline & 100 & 0.8555 & 0.1327 & 0.1337 & 0.6037 & 0.2915 & 0.0894 & 0.3325 & 0.0176 \\
\hline \multirow{2}{*}{$\gamma, A^{3} \Phi-X^{\prime 3} \Delta \ldots$} & 0 & 0.8993 & 0.0948 & 0.0957 & 0.7153 & 0.2322 & 0.0492 & 0.3064 & 0.1349 \\
\hline & 50 & 0.8958 & 0.0980 & 0.0989 & 0.7060 & 0.2381 & 0.0518 & 0.3111 & 0.1218 \\
\hline \multirow{3}{*}{$A, b^{1} \Sigma^{+}-X^{1} \Sigma^{+}$} & 100 & 0.8847 & 0.1079 & 0.1085 & 0.6778 & 0.2552 & 0.0600 & 0.3233 & $\begin{array}{l}0.0866 \\
0.1380\end{array}$ \\
\hline & $\begin{array}{r}0 \\
50\end{array}$ & 0.5161 & 0.3492 & 0.3319 & 0.0584 & 0.1901 & 0.2507 & 0.0105 & $\begin{array}{l}0.1380 \\
0.1343\end{array}$ \\
\hline & $\begin{array}{r}50 \\
100\end{array}$ & 0.5103 & 0.3514 & 0.3335 & 0.0539 & $\begin{array}{l}0.1838 \\
0.1654\end{array}$ & $\begin{array}{l}0.2488 \\
0.2419\end{array}$ & $\begin{array}{l}0.0081 \\
0.0029\end{array}$ & $\begin{array}{l}0.1343 \\
0.1221\end{array}$ \\
\hline \multirow[t]{3}{*}{$B, d^{1} \Delta-c^{1} \Delta \ldots$} & 0 & $\begin{array}{l}0.4933 \\
0.7539\end{array}$ & $\begin{array}{l}0.3576 \\
0.2110\end{array}$ & $\begin{array}{l}0.3378 \\
0.2127\end{array}$ & 0.3780 & 0.3346 & 0.1836 & 0.2285 & 0.0674 \\
\hline & 50 & 0.7483 & 0.2149 & 0.2166 & 0.3672 & 0.3334 & 0.1876 & 0.2199 & $\begin{array}{l}0.0740 \\
0.0942\end{array}$ \\
\hline & 100 & 0.7310 & 0.2266 & 0.2288 & 0.3347 & 0.3283 & 0.1994 & 0.1929 & 0.0942 \\
\hline
\end{tabular}

Franck-Condon Factors for Some Bands of $\alpha, \beta, \gamma, A$, and $B$ Band Systems of ZrO 
TABLE 3

MORSE AND RKR TURNING POINTS FOR DIFFERENT VIBRATIONAL LEVELS OF THE $b^{1 \Sigma^{+}}$AND $X^{1} \Sigma^{+}$STATES OF ZrO*

\begin{tabular}{crrcccc}
\hline \hline $\begin{array}{c}\text { Electronic } \\
\text { State }\end{array}$ & $v$ & $\begin{array}{c}U \\
\left(\mathrm{~cm}^{-1}\right)\end{array}$ & $\begin{array}{c}\text { Morse } \\
r_{\min }\end{array}$ & $\begin{array}{c}\mathrm{RKR} \\
\boldsymbol{r}_{\min }\end{array}$ & $\begin{array}{c}\text { Morse } \\
r_{\max }\end{array}$ & $\begin{array}{c}\mathrm{RKR} \\
r_{\max }\end{array}$ \\
\hline$b^{1} \Sigma^{+} \ldots \ldots$ & 0 & 421.09 & 1.7205 & 1.7205 & 1.8292 & 1.8292 \\
& 1 & 1258.54 & 1.6852 & 1.6851 & 1.8740 & 1.8739 \\
& 2 & 2089.69 & 1.6621 & 1.6620 & 1.9066 & 1.9065 \\
& 3 & 2914.54 & 1.6440 & 1.6439 & 1.9342 & 1.9341 \\
& 4 & 3733.09 & 1.6289 & 1.6287 & 1.9590 & 1.9588 \\
& 5 & 4545.34 & 1.6158 & 1.6155 & 1.9819 & 1.9816 \\
& 6 & 5351.29 & 1.6041 & 1.6038 & 2.0034 & 2.0030 \\
& 7 & 6150.94 & 1.5935 & 1.5931 & 2.0238 & 2.0234 \\
& 8 & 6944.29 & 1.5839 & 1.5834 & 2.0435 & 2.0430 \\
& 9 & 7731.34 & 1.5750 & 1.5744 & 2.0624 & 2.0619 \\
& 10 & 8512.09 & 1.5667 & 1.5660 & 2.0809 & 2.0802 \\
$X^{1} \Sigma^{+} \ldots$ & 0 & 487.39 & 1.6633 & 1.6632 & 1.7642 & 1.7642 \\
& 1 & 1456.96 & 1.6303 & 1.6301 & 1.8057 & 1.8055 \\
& 2 & 2419.64 & 1.6087 & 1.6084 & 1.8359 & 1.8356 \\
& 3 & 3375.38 & 1.5919 & 1.5914 & 1.8615 & 1.8610 \\
& 4 & 4324.19 & 1.5777 & 1.5771 & 1.8843 & 1.8837 \\
& 5 & 5266.08 & 1.5654 & 1.5647 & 1.9054 & 1.9046 \\
& 6 & 6201.05 & 1.5545 & 1.5535 & 1.9252 & 1.9243 \\
& 7 & 7129.09 & 1.5446 & 1.5435 & 1.9441 & 1.9430 \\
& 8 & 8050.21 & 1.5355 & 1.5343 & 1.9621 & 1.9609 \\
& 9 & 8964.40 & 1.5272 & 1.5257 & 1.9796 & 1.9781 \\
& 10 & 9871.67 & 1.5194 & 1.5177 & 1.9965 & 1.9949
\end{tabular}

* All $r$ values are given in $\AA$.

$X^{1} \Sigma^{+}$molecular constants given by Phillips and Davis $(1976 b)$. The $r_{e}$ presented for this electronic state in Table 1 was calculated using equation (6). For the $\mathrm{CuH} A^{1} \Sigma^{+}$and $X^{1} \Sigma^{+}$states we used spectroscopic constants given by Herzberg (1950).

In calculating the transition probability parameters for the $\mathrm{ZrO} \alpha, \beta$, and $\gamma$ band systems, i.e., the transitions involving the triplet states, Schoonveld and Sundaram (1974) found the Morse potential to be an excellent representation of the true potential of the aforementioned band systems of $\mathrm{ZrO}$. In order to test the reliability of the Morse potential for the $\mathrm{ZrO} A$ and $B$ and $\mathrm{CuH}\left(A^{1} \Sigma^{+}-X^{1} \Sigma^{+}\right)$band systems we have also calculated the Rydberg-Klein-Rees (RKR) potentials for the involved electronic states, and compared with the Morse potentials. The energies for each vibrational level are given in Tables 3, 4, and 5 together with the turning points. From the result of this comparison one can also expect the Morse potential to be valid for $\mathrm{ZrO} A$ and $B$ and $\mathrm{CuH}\left(A^{1} \Sigma^{+}-X^{1} \Sigma^{+}\right)$ band systems. These energy curves are given for the rotationless case, but the Morse potential is expected to give reliable results for high rotational levels also. In order to come to this conclusion we have checked the orthogonality of the wave functions for all transitions, by equating the spectroscopic constants of the upper and lower electronic states. We found the diagonal matrix elements to differ from unity by less than $10^{-6}$ and the off-diagonal elements to be in the $10^{-14}$ to $10^{-20}$ range. Morse and RKR potential curves were also calculated for the ZrO triplet electronic states and found to agree up to high vibrational levels. Since part of the turning points are given by Schoonveld and Sundaram (1974), we shall not repeat them here. However, they are available on request.
TABLE 4

MORSE AND RKR TURNINg PoINTS For Different VIBRATIONAL LEVELS OF THE $d^{1} \Delta$ AND $c^{1} \Delta$ STATES OF ZrO*

\begin{tabular}{lrrcccc}
\hline \hline $\begin{array}{c}\text { Electronic } \\
\text { State }\end{array}$ & $v$ & $\begin{array}{c}U \\
\left(\mathrm{~cm}^{-1}\right)\end{array}$ & $\begin{array}{c}\text { Morse } \\
r_{\min }\end{array}$ & $\begin{array}{c}\mathrm{RKR} \\
r_{\min }\end{array}$ & $\begin{array}{c}\text { Morse } \\
r_{\max }\end{array}$ & $\begin{array}{c}\mathrm{RKR} \\
r_{\max }\end{array}$ \\
\hline$d^{1} \Delta \ldots \ldots$ & 0 & 418.96 & 1.7113 & 1.7113 & 1.8202 & 1.8202 \\
& 1 & 1253.04 & 1.6755 & 1.6754 & 1.8646 & 1.8645 \\
& 2 & 2082.00 & 1.6519 & 1.6517 & 1.8967 & 1.8965 \\
& 3 & 2905.84 & 1.6335 & 1.6332 & 1.9238 & 1.9236 \\
& 4 & 3724.56 & 1.6179 & 1.6176 & 1.9480 & 1.9477 \\
& 5 & 4538.16 & 1.6044 & 1.6040 & 1.9703 & 1.9699 \\
& 6 & 5346.64 & 1.5924 & 1.5919 & 1.9912 & 1.9907 \\
& 7 & 6150.00 & 1.5815 & 1.5809 & 2.0110 & 2.0104 \\
& 8 & 6948.24 & 1.5714 & 1.5707 & 2.0299 & 2.0292 \\
& 9 & 7741.36 & 1.5622 & 1.5614 & 2.0482 & 2.0474 \\
& 10 & 8529.36 & 1.5535 & 1.5526 & 2.0659 & 2.0650 \\
${ }^{1} \Delta \ldots$ & 0 & 468.60 & 1.6752 & 1.6752 & 1.7782 & 1.7782 \\
& 1 & 1403.10 & 1.6406 & 1.6406 & 1.8192 & 1.8192 \\
& 2 & 2334.00 & 1.6176 & 1.6177 & 1.8486 & 1.8486 \\
& 3 & 3261.30 & 1.5995 & 1.5995 & 1.8732 & 1.8732 \\
& 4 & 4185.00 & 1.5842 & 1.5841 & 1.8950 & 1.8950 \\
& 5 & 5105.10 & 1.5707 & 1.5707 & 1.9150 & 1.9149 \\
& 6 & 6021.60 & 1.5587 & 1.5587 & 1.9335 & 1.9335 \\
& 7 & 6934.50 & 1.5477 & 1.5477 & 1.9510 & 1.9510 \\
& 8 & 7843.80 & 1.5376 & 1.5376 & 1.9677 & 1.9677 \\
& 9 & 8749.50 & 1.5283 & 1.5282 & 1.9837 & 1.9836 \\
& 10 & 9651.60 & 1.5195 & 1.5194 & 1.9991 & 1.9990
\end{tabular}

* All $r$ values are given in $\AA$.

FCFs for the $\mathrm{ZrO}$ band systems have been reported in Table 2 for some transitions. As expected, the factors do not differ very much for the 0-0 transition even when $J=100$, because of the similarity of the spectroscopic constants of the $\mathrm{ZrO}$ band systems. However, the effect appears beyond 1-1 transitions and is pronounced in the weaker but still observable

TABLE 5

MORSE AND RKR TURNING POINTS FOR Different VIBRATIONAL LEVELS OF THE $A^{1} \Sigma^{+}$AND $X^{1} \Sigma^{+}$STATES OF CuH*

\begin{tabular}{crrcccc}
\hline \hline $\begin{array}{c}\text { Electronic } \\
\text { State }\end{array}$ & $v$ & $\begin{array}{c}U \\
\left(\mathrm{~cm}^{-1}\right)\end{array}$ & $\begin{array}{c}\text { Morse } \\
\boldsymbol{r}_{\min }\end{array}$ & $\begin{array}{c}\text { RKR } \\
\boldsymbol{r}_{\min }\end{array}$ & $\begin{array}{c}\text { Morse } \\
\boldsymbol{r}_{\max }\end{array}$ & $\begin{array}{c}\mathrm{RKR} \\
\boldsymbol{r}_{\max }\end{array}$ \\
\hline$A^{1} \Sigma^{+} \ldots$ & 0 & 838.20 & 1.4453 & 1.4456 & 1.7313 & 1.7316 \\
& 1 & 2448.60 & 1.3689 & 1.3696 & 1.8756 & 1.8763 \\
& 2 & 3971.00 & 1.3233 & 1.3241 & 1.9931 & 1.9940 \\
& 3 & 5405.40 & 1.2900 & 1.2900 & 2.1027 & 2.1035 \\
& 4 & 6751.80 & 1.2639 & 1.2644 & 2.2100 & 2.2105 \\
& 5 & 8010.20 & 1.2426 & 1.2424 & 2.3183 & 2.3181 \\
& 6 & 9180.60 & 1.2248 & 1.2236 & 2.4295 & 2.4283 \\
& 7 & 10263.00 & 1.2098 & 1.2069 & 2.5457 & 2.5429 \\
& 8 & 11257.40 & 1.1969 & 1.1919 & 2.6686 & 2.6636 \\
& 9 & 12163.80 & 1.1859 & 1.1779 & 2.8004 & 2.7924 \\
$X^{1} \Sigma^{+} \ldots$ & 10 & 12982.20 & 1.1764 & 1.1646 & 2.9436 & 2.9317 \\
& 0 & 960.95 & 1.3426 & 1.3433 & 1.6094 & 1.6101 \\
& 1 & 2827.35 & 1.2680 & 1.2701 & 1.7377 & 1.7398 \\
& 2 & 4619.75 & 1.2224 & 1.2258 & 1.8393 & 1.8427 \\
& 3 & 6338.15 & 1.1886 & 1.1932 & 1.9315 & 1.9361 \\
& 4 & 7982.55 & 1.1616 & 1.1673 & 2.0195 & 2.0253 \\
& 5 & 9552.95 & 1.1391 & 1.1459 & 2.1059 & 2.1127 \\
& 6 & 11049.35 & 1.1199 & 1.1277 & 2.1921 & 2.1999 \\
& 7 & 12471.75 & 1.1033 & 1.1120 & 2.2792 & 2.2879 \\
& 8 & 13820.15 & 1.0888 & 1.0982 & 2.3681 & 2.3775 \\
& 9 & 15094.55 & 1.0759 & 1.0860 & 2.4597 & 2.4697 \\
& 10 & 16294.95 & 1.0645 & 1.0750 & 2.5546 & 2.5651 \\
& & & & & & \\
\end{tabular}

* All $r$ values are given in $\AA$. 
TABLE 6

$\bar{r}$-Centroids for Some Bands of $\alpha, \beta, \gamma, A$, ANd $B$ BAND Systems of ZrO

\begin{tabular}{|c|c|c|c|c|c|c|c|c|c|}
\hline Band System & $J$ & $0-0$ & $0-1$ & $1-0$ & $1-1$ & $2-3$ & $3-5$ & $4-5$ & $6-6$ \\
\hline \multirow[t]{3}{*}{$\alpha, C^{3} \Delta-X^{\prime}{ }^{3} \Delta \ldots$} & 0 & 1.7539 & 1.8181 & 1.6977 & 1.7602 & 1.8331 & 1.9005 & 1.8488 & 1.8053 \\
\hline & 50 & 1.7577 & 1.8214 & 1.7020 & 1.7641 & 1.8365 & 1.9036 & 1.8522 & 1.8086 \\
\hline & 100 & 1.7692 & 1.8313 & 1.7150 & 1.7757 & 1.8466 & 1.9129 & 1.8626 & 1.8186 \\
\hline \multirow[t]{3}{*}{$\beta, B^{3} \Pi-X^{\prime}{ }^{3} \Delta \ldots$} & 0 & 1.7445 & 1.8518 & 1.6478 & 1.7511 & 1.8671 & 1.9522 & 1.8826 & 1.7558 \\
\hline & 50 & 1.7483 & 1.8540 & 1.6532 & 1.7549 & 1.8694 & 1.9543 & 1.8849 & 1.7564 \\
\hline & 100 & 1.7596 & 1.8607 & 1.6690 & 1.7664 & 1.8763 & 1.9610 & 1.8921 & 1.7521 \\
\hline \multirow{3}{*}{$\gamma, A^{3} \Phi-X^{\prime}{ }^{3} \Delta \ldots$} & 0 & 1.7431 & 1.8628 & 1.6338 & 1.7496 & 1.8784 & 1.9695 & 1.8942 & 1.7702 \\
\hline & 50 & 1.7468 & 1.8647 & 1.6392 & 1.7534 & 1.8804 & 1.9718 & 1.8962 & 1.7735 \\
\hline & 100 & 1.7580 & 1.8710 & 1.6552 & 1.7648 & 1.8868 & 1.9787 & 1.9027 & 1.7830 \\
\hline \multirow[t]{3}{*}{$A, b^{1} \Sigma^{+}-X^{1} \Sigma^{+}$} & & 1.7439 & 1.7928 & 1.7016 & 1.7508 & 1.8068 & 1.8616 & 1.8270 & 1.7844 \\
\hline & 50 & 1.7475 & 1.7962 & 1.7055 & 1.7545 & 1.8103 & 1.8649 & 1.8319 & 1.7881 \\
\hline & 100 & 1.7584 & 1.8064 & 1.7171 & 1.7659 & 1.8207 & 1.8748 & 1.8501 & 1.7992 \\
\hline \multirow[t]{3}{*}{$B, d^{1} \Delta-c^{1} \Delta \ldots$} & 0 & 1.7464 & 1.8207 & 1.6802 & 1.7510 & 1.8311 & 1.9003 & 1.8403 & 1.8075 \\
\hline & 50 & 1.7502 & 1.8237 & 1.6847 & 1.7547 & 1.8342 & 1.9029 & 1.8435 & 1.8105 \\
\hline & 100 & 1.7614 & 1.8327 & 1.6982 & 1.7658 & 1.8435 & 1.9106 & 1.8528 & 1.8199 \\
\hline
\end{tabular}

bands. The $\bar{r}$-centroids for the $\mathrm{ZrO}$ band systems are given in Table 6 . All FCFs and $\bar{r}$-centroids calculated by us for the rotationless case agree very well with previous values given by Nicholls and Tyte (1967) and Schoonveld and Sundaram (1974).

Since Rai, Dube, and Singh (1971) reported the electronic transition moment of the $\operatorname{ZrO} \alpha\left(C^{3} \Delta-X^{\prime}{ }^{3} \Delta\right)$ band system to vary as

$$
R_{e}(\bar{r})=\text { const. }\left(1+0.015 \bar{r}+0.03 \bar{r}^{2}\right),
$$

we have also calculated the relative band strengths for this band system. They are shown in Table 7. It should be noted that these relative band strengths are calculated without use of the usual $\bar{r}$-centroid approximation.

As we reported, to our knowledge the FCFs for $\mathrm{CuH}\left(A^{1} \Sigma^{+}-X^{1} \Sigma^{+}\right)$band system are not available in the literature. Therefore we decided to give FCFs for all transitions with $v^{\prime}, v^{\prime \prime} \leq 4$ and for $J=0,30$, and 60 . For the hypothetical $Q$-branch they can be found in Table 8. It is noticed that, even for the $0-0$ and $0-1$ transitions, FCFs differ by $50 \%$ while $J$ is increased from 0 to 60 . Pronounced effects are seen in $1-1,2-0$,

TABLE 7

Relative Band Strength Factors for the $\mathrm{ZrO} \alpha\left(C^{3} \Delta-X^{\prime 3} \Delta\right)$ BAND SYSTEM*

\begin{tabular}{lrlllll}
\hline \hline$v^{\prime}$ & $J$ & $v^{\prime \prime}=0$ & $v^{\prime \prime}=1$ & $v^{\prime \prime}=2$ & $v^{\prime \prime}=3$ & $v^{\prime \prime}=4$ \\
\hline $0 \ldots$ & 0 & 0.8450 & 0.3393 & 0.0654 & 0.0077 & 0.0006 \\
& 50 & 0.8376 & 0.3447 & 0.0680 & 0.0082 & 0.0007 \\
& 100 & 0.8157 & 0.3606 & 0.0758 & 0.0097 & 0.0008 \\
$1 \ldots$ & 0 & 0.3237 & 0.3099 & 0.4449 & 0.1527 & 0.0262 \\
& 50 & 0.3284 & 0.2977 & 0.4471 & 0.1575 & 0.0276 \\
& 100 & 0.3421 & 0.2623 & 0.4521 & 0.1722 & 0.0323 \\
$2 \ldots$ & 0 & 0.0662 & 0.4127 & 0.0687 & 0.4178 & 0.2342 \\
& 50 & 0.0689 & 0.4133 & 0.0610 & 0.4143 & 0.2400 \\
& 100 & 0.0773 & 0.4134 & 0.0409 & 0.4018 & 0.2568 \\
$3 \ldots$ & 0 & 0.0094 & 0.1495 & 0.3737 & 0.0008 & 0.3282 \\
& 50 & 0.0101 & 0.1543 & 0.3682 & 0.0001 & 0.3199 \\
& 100 & 0.0123 & 0.1683 & 0.3500 & 0.0013 & 0.2939 \\
$4 \ldots$ & 0 & 0.0010 & 0.0310 & 0.2205 & 0.2795 & 0.0225 \\
& 50 & 0.0011 & 0.0329 & 0.2252 & 0.2695 & 0.0275 \\
& 100 & 0.0015 & 0.0392 & 0.2382 & 0.2392 & 0.0444 \\
& & & & & &
\end{tabular}

* Calculated using $R_{e}(\bar{r})=$ const $\left(1+0.015 \bar{r}+0.03 \bar{r}^{2}\right)$.
TABLE 8

Rotational Dependence of Franck-Condon FaCtors FOR THE CUH $A^{1} \Sigma^{+}-X^{1} \Sigma^{+}$BAND SYSTEM

\begin{tabular}{lrlllll}
\hline \hline$v^{\prime}$ & \multicolumn{1}{c}{$J$} & $v^{\prime \prime}=0$ & $v^{\prime \prime}=1$ & $v^{\prime \prime}=2$ & $v^{\prime \prime}=3$ & $v^{\prime \prime}=4$ \\
\hline $0 \ldots$ & 0 & 0.7147 & 0.2609 & 0.0238 & 0.0006 & 0.0000 \\
& 30 & 0.7072 & 0.2649 & 0.0270 & 0.0009 & 0.0000 \\
& 60 & 0.4155 & 0.4037 & 0.1509 & 0.0273 & 0.0024 \\
$1 \ldots$ & 0 & 0.2101 & 0.3045 & 0.4115 & 0.0709 & 0.0030 \\
& 30 & 0.2149 & 0.2863 & 0.4129 & 0.0812 & 0.0045 \\
& 60 & 0.2784 & 0.0016 & 0.2787 & 0.3107 & 0.1121 \\
$2 \ldots$ & 0 & 0.0540 & 0.2559 & 0.0823 & 0.4613 & 0.1376 \\
& 30 & 0.0558 & 0.2593 & 0.0645 & 0.4482 & 0.1581 \\
& 60 & 0.1413 & 0.0863 & 0.0995 & 0.0434 & 0.3091 \\
$\ldots$ & 0 & 0.0146 & 0.1100 & 0.2070 & 0.0032 & 0.4275 \\
& 30 & 0.0151 & 0.1150 & 0.2005 & 0.0001 & 0.3892 \\
& 60 & 0.0682 & 0.1091 & 0.0028 & 0.1273 & 0.0206 \\
$4 \ldots$ & 0 & 0.0043 & 0.0416 & 0.1392 & 0.1222 & 0.0179 \\
& 30 & 0.0045 & 0.0444 & 0.1438 & 0.1047 & 0.0359 \\
& 60 & 0.0333 & 0.0846 & 0.0073 & 0.0695 & 0.0170 \\
\end{tabular}

and 2-1 transitions. For the $0-2$ transitions the FCFs for $J=60$ differ from that when $J=0$ by a factor of 6. This leads us to believe that for $\mathrm{CuH}\left(A^{1} \Sigma^{+}-X^{1} \Sigma^{+}\right)$ band system the vibration-rotation interaction cannot be neglected in calculating FCFs. The $\bar{r}$-centroids for

TABLE 9

Rotational DePENDENCE OF THE $\bar{r}$-CENTROIDS FOR THE CUH $A^{1} \Sigma^{+}-X^{1} \Sigma^{+}$BAND SYSTEM

\begin{tabular}{lrlllll}
\hline \hline$v^{\prime}$ & $J^{\prime \prime}$ & $v^{\prime \prime}=0$ & $v^{\prime \prime}=1$ & $v^{\prime \prime}=2$ & $v^{\prime \prime}=3$ & $v^{\prime \prime}=4$ \\
\hline $0 \ldots$ & 0 & 1.5381 & 1.7196 & 1.9873 & 2.3786 & 2.7424 \\
& 30 & 1.6374 & 1.8321 & 2.0990 & 2.4392 & 2.8017 \\
& 60 & 2.0321 & 2.2240 & 2.4342 & 2.6708 & 2.9529 \\
$1 \ldots$ & 0 & 1.3813 & 1.5940 & 1.7558 & 2.0146 & 2.3871 \\
& 30 & 1.4761 & 1.6996 & 1.8749 & 2.1328 & 2.4599 \\
& 60 & 1.9208 & 2.3650 & 2.3182 & 2.5199 & 2.7518 \\
$2 \ldots$ & 0 & 1.2695 & 1.4235 & 1.6861 & 1.7959 & 2.0452 \\
& 30 & 1.3554 & 1.5278 & 1.8031 & 1.9224 & 2.1707 \\
& 60 & 1.8328 & 2.0353 & 2.1744 & 2.4612 & 2.6223 \\
$3 \ldots$ & 0 & 1.1888 & 1.3063 & 1.4739 & 2.1780 & 1.8409 \\
& 30 & 1.2651 & 1.4037 & 1.5889 & 4.8836 & 1.9759 \\
& 60 & 1.7641 & 1.9481 & 1.9337 & 2.3042 & 2.3962 \\
$4 \ldots$ & 0 & 1.1292 & 1.2216 & 1.3488 & 1.5386 & 1.4326 \\
& 30 & 1.1973 & 1.3104 & 1.4591 & 1.6674 & 1.6674 \\
& 60 & 1.7122 & 1.8867 & 2.1393 & 2.2091 & 2.4989 \\
\hline
\end{tabular}


TABLE 10

Franck-Condon Factors for the $R$ and $P$ Branch of the CuH $(A-X)$ Band

\begin{tabular}{|c|c|c|c|c|c|c|c|c|}
\hline \multirow[b]{2}{*}{$J^{\prime \prime}$} & \multicolumn{4}{|c|}{$R\left(J^{\prime \prime}\right)$} & \multicolumn{4}{|c|}{$P\left(J^{\prime \prime}+1\right)$} \\
\hline & $0-0$ & $0-1$ & $1-0$ & $1-1$ & $0-0$ & $0-1$ & $1-0$ & $1-1$ \\
\hline $\begin{array}{l}0 \ldots \ldots \\
1 \ldots \ldots \\
2 \ldots \ldots \\
3 \ldots \ldots \\
4 \ldots \ldots \\
5 \ldots \ldots\end{array}$ & $\begin{array}{l}0.7138 \\
0.7130 \\
0.7121 \\
0.7113 \\
0.7105 \\
0.7097\end{array}$ & $\begin{array}{l}0.2615 \\
0.2622 \\
0.2628 \\
0.2635 \\
0.2641 \\
0.2647\end{array}$ & $\begin{array}{l}0.2106 \\
0.2111 \\
0.2115 \\
0.2119 \\
0.2124 \\
0.2128\end{array}$ & $\begin{array}{l}0.3030 \\
0.3015 \\
0.3000 \\
0.2985 \\
0.2970 \\
0.2956\end{array}$ & $\begin{array}{l}0.7156 \\
0.7165 \\
0.7173 \\
0.7183 \\
0.7192 \\
0.7201\end{array}$ & $\begin{array}{l}0.2602 \\
0.2595 \\
0.2588 \\
0.2581 \\
0.2574 \\
0.2566\end{array}$ & $\begin{array}{l}0.2097 \\
0.2092 \\
0.2087 \\
0.2083 \\
0.2078 \\
0.2073\end{array}$ & $\begin{array}{l}0.3060 \\
0.3075 \\
0.3091 \\
0.3106 \\
0.3122 \\
0.3138\end{array}$ \\
\hline $\begin{array}{c}6 \ldots \ldots \\
7 \ldots \ldots \\
8 \ldots \ldots \\
9 \ldots \ldots \\
10 \ldots \ldots\end{array}$ & $\begin{array}{l}0.7088 \\
0.7080 \\
0.7072 \\
0.7064 \\
0.7056\end{array}$ & $\begin{array}{l}0.2653 \\
0.2654 \\
0.2665 \\
0.2670 \\
0.2676\end{array}$ & $\begin{array}{l}0.2133 \\
0.2137 \\
0.2142 \\
0.2146 \\
0.2150\end{array}$ & $\begin{array}{l}0.2941 \\
0.2926 \\
0.2912 \\
0.2897 \\
0.2882\end{array}$ & $\begin{array}{l}0.7210 \\
0.7219 \\
0.7229 \\
0.7238 \\
0.7247\end{array}$ & $\begin{array}{l}0.2559 \\
0.2551 \\
0.2544 \\
0.2536 \\
0.2529\end{array}$ & $\begin{array}{l}0.2068 \\
0.2063 \\
0.2058 \\
0.2054 \\
0.2049\end{array}$ & $\begin{array}{l}0.3154 \\
0.3169 \\
0.3185 \\
0.3200 \\
0.3216\end{array}$ \\
\hline $\begin{array}{l}11 \ldots \ldots \\
12 \ldots \ldots \\
13 \ldots \ldots \\
14 \ldots \ldots \\
15 \ldots \ldots\end{array}$ & $\begin{array}{l}0.7048 \\
0.7039 \\
0.7030 \\
0.7022 \\
0.7012\end{array}$ & $\begin{array}{l}0.2682 \\
0.2688 \\
0.2694 \\
0.2700 \\
0.2707\end{array}$ & $\begin{array}{l}0.2155 \\
0.2160 \\
0.2164 \\
0.2169 \\
0.2174\end{array}$ & $\begin{array}{l}0.2866 \\
0.2851 \\
0.2835 \\
0.2818 \\
0.2801\end{array}$ & $\begin{array}{l}0.7256 \\
0.7265 \\
0.7274 \\
0.7282 \\
0.7291\end{array}$ & $\begin{array}{l}0.2521 \\
0.2514 \\
0.2507 \\
0.2499 \\
0.2492\end{array}$ & $\begin{array}{l}0.2044 \\
0.2039 \\
0.2035 \\
0.2030 \\
0.2026\end{array}$ & $\begin{array}{l}0.3231 \\
0.3246 \\
0.3260 \\
0.3274 \\
0.3287\end{array}$ \\
\hline
\end{tabular}

the $\mathrm{CuH}\left(A^{1} \Sigma^{+}-X^{1} \Sigma^{+}\right)$band system are given in Table 9 . Regarding these values, we would like to mention that in some cases, where the overlap integral is very small, the $\bar{r}$-centroids could be unreliable. This is probably the problem with the $\bar{r}$-centroid $\bar{r}_{33}(J=30)$ $=4.8836$. However, it would be interesting to study the criteria of the minimum and maximum $\bar{r}$-centroids to be used in generating the $R_{e}(\bar{r})$ functions.

Finally, in Table 10 we give the FCFs for the $R$ and $P$ branches of the $0-0,0-1,1-0$, and $1-1$ bands of $\mathrm{CuH}$ $\left(A^{1} \Sigma^{+}-X^{1} \Sigma^{+}\right)$band system for $J$ up to 15 . These factors should be useful, together with Hönl-London factors, in calculating the rotational intensity structure of these bands. It is interesting to note that for the $0-0$ band, for which Wojslaw and Perry (1976) reported a peculiar $J$-dependence, the FCFs increase with $J$ for the $P$ branch and decrease for the $R$ branch.

In view of the great number of data generated for all the studied band systems, larger vibrational arrays with full rotational dependence are not published here but are available from the authors on request.

We are indebted to Dr. G. Bandyopadhyay of the Argonne National Laboratory for providing us copies of some needed references.

\section{REFERENCES}

Balfour, W. J., and Tatum, J. B. 1973, J. Molec. Spectrosc., 48, 313.

Chakraborty, B. P., Pan, Y. K., and Chang, T. Y. 1971, J. Chem. Phys., 55, 5147.

Chang, T. Y., and Karplus, M. 1970, J. Chem. Phys., 52, 783. Gallas, J. A. C., Grieneisen, H. P., and Chakraborty, B. P. 1978, J. Chem. Phys., 69, 612-614.

Hauge, Ö. 1971, Astr. Ap., 10, 73.

Herzberg, G. 1950, Molecular Spectra and Molecular Structure, Spectra of Diatomic Molecules (2d ed.; New York: van Nostrand-Reinhold).

Keenan, P. C., and Morgan, W. W. 1951, in Classification of Stellar Spectra in Astrophysics; A Topical Symposium, ed. J. A. Hynek (New York: McGraw-Hill).

Learner, R. C. M. 1962, Proc. Roy. Soc. London, A, 269, 311. Liszt, H. S., and Smith, Wm. S. 1971, J. Quant. Spectrosc. Rad. Transf., 11, 1043.

Nicholls, R. W. 1977, Ann. Rev. Astr. Ap., 15, 197.
Nicholls, R. W., and Tyte, D. C. 1967, Proc. Phys. Soc., 91, 489.

Phillips, J. G., and Davis, S. P. 1976a, Ap. J., 206, 632.

- 1976b, Ap. J. Suppl., 32, 537.

Rai, J. N., Dube, P. S., and Singh, N. L. 1971, J. Sci. Res. Banaras Hindu Univ., 21, 71.

- 1977, Phys. Abstr., 80, 5042 (Abst. No. 68079).

Schoonveld, L., and Sundaram, S. 1974, Ap. J., 192, 207.

Singh, P. D., and Pathak, A. N. 1967a, Proc. Phys. Soc., 90, 543.

. 1967b, Proc. Phys. Soc., 91, 497.

Tatum, J. B. 1967, Ap. J. Suppl., 14, 21.

Uhler, U., and Åkerlind, L. 1956, Ark. Fis., 10, 431.

Veits, I. V., Gurvisch, L. V., Kobylianskii, A. I., Smirnov, A. D., and Suslor, A. A. 1974, J. Quant. Spectrosc. Rad. Transf., 14, 221.

Wojslaw, R. S., and Peery, B. F., Jr. 1976, Ap. J. Suppl., 31, 75.

B. P. Chakraborty, R. E. Francke, J. A. C. Gallas, and H. P. Grieneisen: Departamento de Físico-Química, Instituto de Química, U.F.R.G.S., 90.000, Porto Alegre, RS, Brasil 